\title{
THE PREVENTION OF POST-PARTUM HAEMORRHAGE; A RE-APPRAISAL
}

\author{
By E. G. JonAs, M.B., F.R.C.S., M.R.C.O.G. \\ Obstetric and Gynaecological Registrar, Woolwich Group of Hospitals, London, S.E.18; formerly Residenit Medical Officer, \\ City of London Maternity Hospital, London, N.4
}

\section{Introduction}

In a recent report on maternal mortality (Ministry of Health, 1957), haemorrhage was the second-largest cause of death.

Since the Registrar-General's returns for England and Wales fail to differentiate between haemorrhage of pregnancy, of labour, and in the puerperium, it is impossible to compute accurately the national incidence of post-partum haemorrhage. There is no doubt, however, that it is of prime importance as a cause of maternal mortality and morbidity. Modern advances in the treatment of haemorrhagic shock, notably bloodtransfusion, have saved many lives which would formerly have been lost. But real progress in this matter can only be made by reducing the incidence of post-partum haemorrhage. Clearly, this must be achieved by preventive means.

From a practical point of view, and therefore for purposes of discussion in this paper, the crux of the problem is primary ' atonic' post-partum haemorrhage. This is defined as bleeding from the placental site in excess of $20 \mathrm{oz}$. $(570 \mathrm{ml}$.) within 24 hours of delivery.

The incidence of post-partum haemorrhage in British clinics varies, but some recent reports quote rates of 6 to 16 per cent. (Lister, 1950; Hammond, 1952; de Boer, 1955). The incidence abroad varies even more, but account must be taken of differences in definition: von Massenbach et al. (195I) reported a rate of 24.5 per cent.

Most clinics in this country today practise a preventive regime, consisting in outline of:

I. Ante- and intra-natal recognition of factors predisposing to post-partum haemorrhage: these are divisible into general and local, and are well-known.

2. Improved conduct of the third stage of labour: unnecessary uterine manipulation is nowadays discouraged. In the event of retained placenta, its manual removal is a safe and effective procedure under suitable conditions.

3. Prophylactic use of oxytocics: this has made it possible to correct failure of uterine contraction and retraction. In selected patients, an oxytocic is administered before the end of the second stage of labour; in others, it is given after expulsion of the placenta.

\section{Present Investigation}

Dissatisfaction with the incidence of postpartum haemorrhage has led to a more extensive, and even routine use of oxytocics before delivery of the baby. Thus, at the City of London Maternity Hospital, it was felt that a post-partum haemorrhage rate of 6.I per cent. over the first nine months of 1954 (see Table r) could be improved upon in this way. It should be noted that the incidence of manual removal of the placenta over the same period was 1.76 per cent. (see Table 2).

The method adopted consisted of the intramuscular injection of an oxytocic, ergometrine (mg. 0.5 ) or methergine ([Sandoz] I ml.), and hyaluronidase ('hyalase'), 1,000 units, with the crowning of the foetal head as first proposed by Kimbell (1954). The enzyme hyaluronidase aids the absorption of substances introduced into the tissue-spaces. Kimbell's method has, surprisingly, only evoked a scant reaction: Dumoulin alone (1955) gave it his unqualified support, and Denny (1956) indicated provisional approval. On the other hand, no serious disapproval has been registered.

Patients at the City of London Maternity Hospital are assigned in strict rotation at booking to one of three services. Random selection was ensured by allocating patients on services $I$ and 2 to the experimental group, while patients on service 3 composed the control group. However, the practice of giving intra-venous ergometrine with the anterior shoulder at certain spontaneous, and at operative deliveries, especially those conducted under general anaesthesia, was maintained (Group 3, see below). Cases of abortion, and patients subjected to caesarian section were excluded from this investigation.

In the two years' period between October 1954 


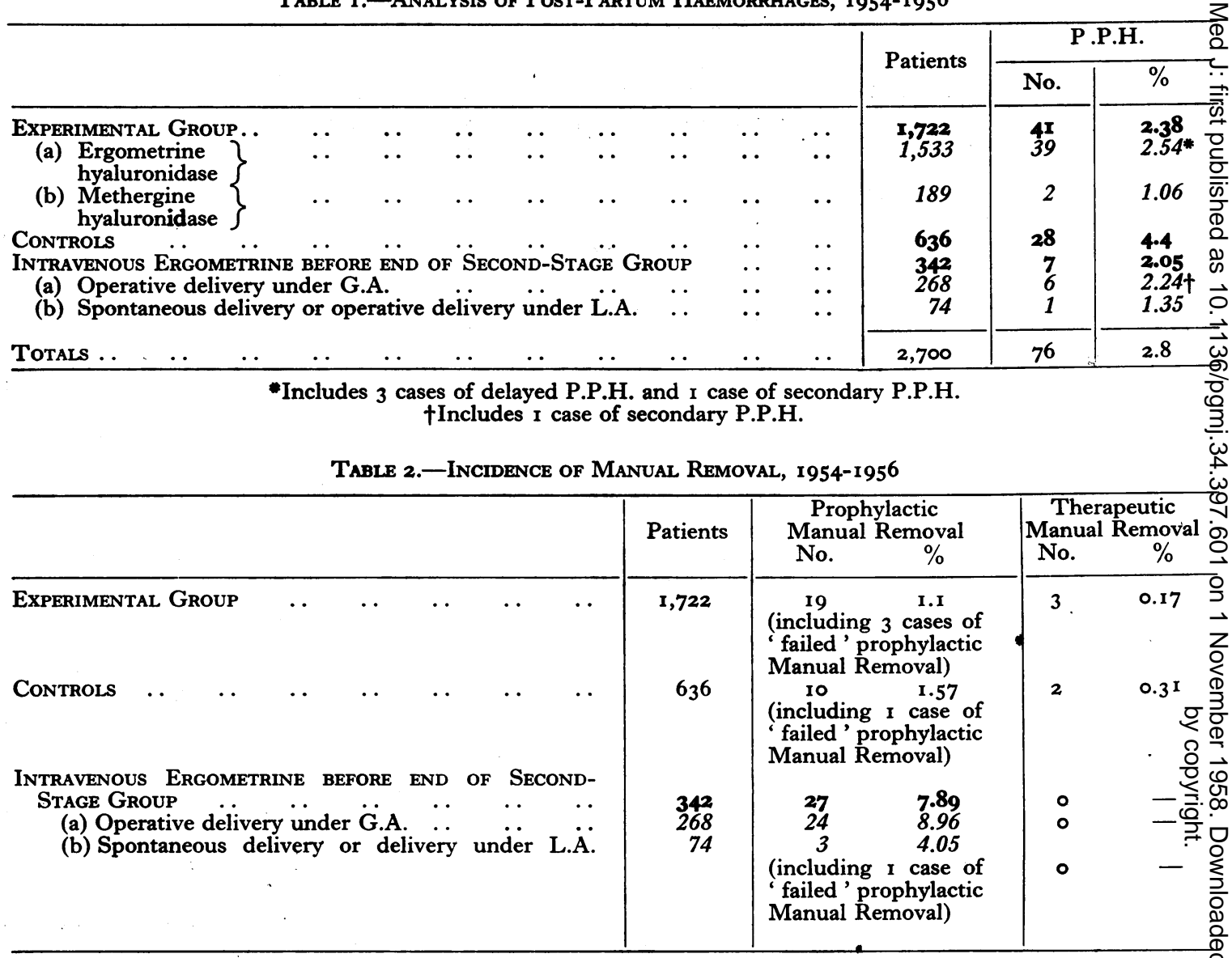

Overall Manual Removal Rate $=\mathbf{2 . 2 6} \%$

(In first 9 months of 1954,17 Manual Removals in 96r deliveries, i.e. 1.76\%)

to September 1956, 2,700 patients were delivered vaginally after 28 weeks' gestation.

They have been divided into three groups, as follows:

\section{Group I}

The experimental group of patients was given an intramuscular injection of either ergometrine (mg. 0.5 ) or methergine ( $1 \mathrm{ml}$.) and hyaluronidase ( 1,000 units) before the end of the second stage, i.e. with the crowning of the foetal head.

\section{Group 2}

The control group of patients was sometimes given an oxytocic during the third stage to arrest bleeding from the placental site. More usually, they received an intramuscular/intra-venous injection of oxytocic after completion of the third stage. Some patients in this group had no oxytocic at all.

\section{Group 3}

These patients were given intra-venous ergo metrine before the end of the second stage, eithe $\mathrm{B}$. at operative deliveries under general anaesthesià or at certain spontaneous deliveries (because of history of post-partum haemorrhage, or anaemia multiple pregnancy, hydramnios or fibroids) and at operative deliveries under local anaesthesią?

Analysis of post-partum haemorrhages in this two years' period (see Table I) shows that in:

Group I (the experimental group), I,53\% patients were given the ergometrine-hyaluronidase combination, with 39 instances of post-partums haemorrhage (2.54 per cent.); these included three cases of delayed, and one case of secondary haemorrhage. A further 189 patients had the methergine-hyaluronidase combination, with twके post-partum haemorrhages (I.06 per cent.), making+ a total of 1,722 patients and 41 post-partum hae $=\bar{O}$ morrhages (2.38 per cent.) in this group. 
Group 2 (the control group), there were $6{ }_{3} 6$ patients, 28 of which had a post-partum haemorrhage (4.4 per cent.).

In both these groups, there were avoidable as well as unavoidable cases of post-partum haemorrhage; however, they were evenly distributed, so that their omission or inclusion does not alter the above, statistically very significant results.

Group 3 (intra-venous ergometrine before end of second stage): 268 patients had an operative delivery under general anaesthesia, with six instances of post-partum haemorrhage (2.24 per cent.); these included one case of secondary bleeding. A further 74 patients had a spontaneous delivery, or an operative delivery under local anaesthesia, with one case of post-partum haemorrhage (I.35 per cent.), making a total of 342 patients and seven post-partum harmorrhages (2.05 per cent.) in this group.

The over-all post-partum haemorrhage rate in the two years' period between October 1954 to September 1956, was therefore 2.8 per cent.

The incidence of manual removal of the placenta in the two years' period (see Table 2) must next be considered.

Retention of the placenta may be associated with little or no blood loss, but bleeding can be such that manual removal has to be undertaken to prevent a post-partum haemorrhage (prophylactic manual removal). In cases where a post-partum haemorrhage has already occurred, but with the placenta still retained, manual removal is done to limit the severity of the haemorrhage (therapeutic removal).

Group I (the experimental group): in 1,722 patients, I9 prophylactic manual removals were done (I.I per cent.), but in three cases, a postpartum haemorrhage could not be forestalled. There were also three instances of therapeutic manual removal (0.17 per cent.).

Group 2 (the control group): in 636 patients, ten prophylactic manual removals were performed (1.57 per cent.), but in one case it was impossible to prevent a post-partum haemorrhage. There were also two instances of therapeutic manual removal ( 0.3 per cent.).

Group 3 (intra-venous ergometrine before end of second stage): in 268 patients who had an operative delivery under general anaesthesia, 24 'prophylactic' manual removals were performed (8.96 per cent.). Most of these were done purely to shorten the period of anaesthesia. A further 74 patients were delivered spontaneously, or had an operative delivery under local anaesthesia, with three instances of prophylactic manual removal (4.05 per cent.), making a total of 342 patients, 27 of which had a manual removal (7.89 per cent.) in this group.
The over-all manual removal rate in the two years' period between October 1954 to September 1956, was therefore 2.3 per cent.

\section{Discussion}

As indicated in the introductory remarks, the incidence of post-partum haemorrhage can only be reduced by preventive means. For these to be effective, it is necessary to understand the mechanism of excessive bleeding from the placental site.

At the present time, the consensus of opinion regards as its prime cause some aberration from the normal of the pattern of uterine contraction and retraction during the third stage. The results 8 of this may be interference with the complete $\exists$. separation of the placenta, and/or inefficient compression of utero-placental vessels opened-up in the spongy layer of the decidua basalis.

Their interplay may well aggravate the bleeding, but it must be stressed that both stem from disordered uterine action, and that there is no causeand-effect relationship between them.

Abnormal shape or attachment of the placenta, and disorders in the coagulability of the blood have been relegated to places of subsidiary importance.

Of the methods specifically designed to preven 8 post-partum haemorrhage, routine elective manuas removal, warmly commended by Hoffman (1954) lays itself open to criticism; it necessitates general anaesthetic, and places undue emphasis on the aetiological role of abnormal shape or attachment of the placenta.

Routine administration of oxytocic before the birth of the baby was first put into practice by Schumacher (1932), using pituitrin. Davis and Boynton (1942) substituted ergometrine for pituitrin. A very large literature on experiences with this method has accumulated. This literature has recently been thoroughly reviewed, and a further large-scale trial of the method conducted by Soiva (1954). His conclusions, which appear to summarise current thought, are:

I. In normal deliveries, routine prophylactic use of oxytocics effectively reduces the incidence of post-partum haemorrhage without serious disadvantages. This can to some extent be achieved by intra-muscular administration, but the intra-venous route produces considerably better results.

2. In operative deliveries, especially when conducted under general anaesthesia, a marked tendency to post-partum haemorrhage can be 0 greatly diminished by intra-venous prophylaxis.

3. The prophylactic use of oxytocics has no undesirable side-effects on either mother or child.

4. Intra-venous prophylaxis does appreciably 
raise the incidence of retained placenta, and thus of manual removal. This is not the case when oxytocic is injected intra-muscularly.

Jeffcoate (1950) stated: 'Oxytocin does not change the quality of uterine action, it intensifies both normal and abnormal contractions alike.' These remarks are probably applicable to oxytocics also. But, though this method may also fail to solve the basis of the mechanism of post-partum haemorrhage, it does at least arrest bleeding by inducing compression of the utero-placental vessels that have been opened up at the placental site. If the oxytocic at the same time accentuates some abnormal pattern of uterine activity in the third stage, placental separation will be further interfered with, leading to retained placenta.

Routine intra-venous administration of oxytocic before the birth of the baby, then, has many advantages, and few disadvantages. Nevertheless, it seems that these latter have prevented the universal adoption of the method, at any rate in this country. Large-scale domiciliary midwifery, and statutory difficulties with intravenous administration of drugs by non-medical personnel have probably been the chief stumbling-blocks.

The oxytocic-hyaluronidase combination, injected intra-muscularly before the birth of the baby (ideally with the crowning of the head) constitutes a valuable compromise in normal deliveries, since it significantly reduces the incidence of post-partum haemorrhage without increasing the manual removal rate. As oxytocic alone, administered in this way, is not as effective (Daley, I95I; Kimbell, 1954; Soiva, 1954; Reiss, 1955), this must be attributed to the addition of hyaluronidase. The use of this combination is not advocated in operative deliveries, because intra-venous prophylaxis is definitely more effective here (Soiva, I954; see also Table I).

In conclusion, it is suggested that administration of the oxytocic-hyaluronidase combination, given intra-muscularly before the birth of the baby, is suitable for the prevention of post-partum haemorrhage in normal deliveries, both in domiciliary and hospital practice. These stipulations all imply that the method may be used by midwives. In the trial here reported, it should be noted that it was not necessary to modify the conduct of the third stage of labour; the placenta was delivered as soon as signs of its descent were detected. The Brandt-Andrews manoeuvre, recommended by Kimbell (1954), was scarcely ever used, and then only by a doctor.

If there are obstetricians or midwives who look upon the preventive concept with doubt and suspicion, it is perhaps because they dislike the association with it of the word ' routine,' which may be objectionable in other contexts. But it is only by the routine practice of a suitable preventive measure that one can hope to reduce the grave problem of post-partum haemorrhage.

\section{Summary}

The method of intra-muscular administration of oxytocic and hyaluronidase before the end of the second stage of labour has been re-appraised. Used on an extensive scale over a two years' period at the City of London Maternity Hospital, it has reduced the incidence of post-partum haemorrhage from 6.I per cent. to 2.8 per cent.; at the same time, the over-all manual removal rate only rose from 1.8 per cent to 2.3 per cent. Since the manual removal rate in the experimental group of cases was actually lower than in the control group, this slight increase cannot be ascribed to this method. It was, in fact, due to the use of intra-venous ergometrine with the delivery of the anterior shoulder in certain spontaneous, and in operative vaginal deliveries.

It is therefore concluded that this method is well-suited for routine prophylactic use in normal deliveries, either in the home or in hospital, and that it may be used by midwives.

In operative vaginal deliveries, which are normally undertaken by medical personnel, pro? phylaxis with intra-venous oxytocic is preferables

\section{Acknowledgments}

I wish to thank Mr. R. Christie Brown, Mr. J. V. O'Sullivan, Mr. D. B. Fraser, Mr. C. W. Kimbell and Mr. I. A. Donaldson for permission to study their cases.

I am grateful to Dr. P. E. Polani for his kindness in dealing with the statistics.

I am specially indebted to the Midwives of the Labour-ward for their unfailingly helpful cooperation.

\section{BIBLIOGRAPHY}

DE BOER, C. H. (1955), Brit. med. F., ii, I187.

DALEY, D. (1951), . Obstet. Gynaec. Brit. Emp., 58, 388.

DAVIS, M. E., and BOYNTON, M. W. (1942), Amer. F. Obstet. Gynec., 43, 775.

DENNY, F. (1956), Brit. med. F., i, 108.

DUMOULIN, J. G. (1955), Ibid., ii, I449.

HAMMOND, G. T. (1952), f. Obstet. Gynaec. Brit. Emp., 49, 493. HOFFMAN, R. L. (1954), Amer. F. Obstet. Gynec., 68, 645.

JEFFCOATE, T. N. A. (1950), ' Modern Trends in Obstetrics and Gynaecology ' (London), p. 244.

KIMBELL, N. (1954), Brit. med. $\mathcal{F}$., ii, 130.

LISTER, U. (1950), Ғ. Obstet. Gynaec. Brit. Emp., 57, 210.

VON MASSENBACH, W. DIECKMANN, C., and HICKL, TH. (I95I), Geburts. u. Frauenheilk., II, 525.

Ministry of Health (1957) Report on Confidential Enquiries into Maternal Deaths in England and Wales, I952-1954. H.M. Stationery Office.

REISS, H. (1955), Brit. med. F., ii, 1622.

SCHUMACHER, P. (1932), Zbl. Gynäk., 56, 1456.

SOIVA, K. (1954), Ann. Chir. Gynaec. Fenn., 43, Suppl. 1. 